\title{
Topoisomerase II $\beta$ Selectively Regulates Motor Neuron Identity and Peripheral Connectivity through Hox/Pbx-Dependent Transcriptional Programs
}

\author{
[DMichaela Edmond, ${ }^{1}$ 일ia Hanley, ${ }^{2}$ and ${ }^{-P}$ Polyxeni Philippidou ${ }^{1}$
}

\section{DOI:http://dx.doi.org/10.1523/ENEURO.0404-17.2017}

${ }^{1}$ Department of Neurosciences, Case Western Reserve University School of Medicine, Cleveland, OH 44106 and ${ }^{2}$ Department of Neuroscience and Physiology, Neuroscience Institute, NYU School of Medicine, New York, NY 10016

\begin{abstract}
Vital motor functions, such as respiration and locomotion, rely on the ability of spinal motor neurons (MNs) to acquire stereotypical positions in the ventral spinal cord and to project with high precision to their peripheral targets. These key properties of MNs emerge during development through transcriptional programs that dictate their subtype identity and connectivity; however, the molecular mechanisms that establish the transcriptional landscape necessary for MN specification are not fully understood. Here, we show that the enzyme topoisomerase II $\beta$ (Top2 $\beta$ ) controls MN migration and connectivity. Surprisingly, Top $2 \beta$ is not required for MN generation or survival but has a selective role in columnar specification. In the absence of Top $2 \beta$, phrenic MN identity is eroded, while other motor columns are partially preserved but fail to cluster to their proper position. In Top2 $\beta-/-$ mice, peripheral connectivity is impaired as MNs exhibit a profound deficit in terminal branching. These defects likely result from the insufficient activation of $\mathrm{Hox} / \mathrm{Pbx}$-dependent transcriptional programs as Hox and $\mathrm{Pbx}$ genes are downregulated in the absence of Top2 $\beta$. Top2 $\beta$ mutants recapitulate many aspects of $P b x$ mutant mice, such as $\mathrm{MN}$ disorganization and defects in medial motor column (MMC) specification. Our findings indicate that Top2 $\beta$, a gene implicated in neurodevelopmental diseases such as autism spectrum disorders, plays a critical, cellspecific role in the assembly of motor circuits.
\end{abstract}

Key words: Hox genes; motor neurons; Pbx genes; phrenic motor column; topoisomerase II $\beta$

\section{Significance Statement}

The acquisition of motor neuron (MN) identity is a critical step in the assembly of motor circuits but the molecular pathways underlying $\mathrm{MN}$ specification remain unclear. Here, we show that the enzyme topoisomerase II $\beta$ (Top2 $\beta$ ) differentially controls MN subtype specification. In the absence of Top2 $\beta$ phrenic MNs do not develop and mice die due to respiratory failure, while other MN subtypes are partially preserved, demonstrating a phrenic-specific critical role for Top2 $\beta$. We show that Top2 $\beta$ acts via Hox/Pbx-dependent transcriptional programs to control $\mathrm{MN}$ organization and medial motor column (MMC) specification, thus unraveling a key step in the genetic hierarchy that underlies $\mathrm{MN}$ development.

\section{Introduction}

Topoisomerases are highly conserved enzymes essential for solving topological problems that arise due to the DNA double helical structure during chromosome segre-

Received November 22, 2017; accepted December 5, 2017; First published December 11, 2017.

The authors declare no competing financial interests. gation, DNA replication and transcription (Wang, 2002). Enzymes belonging to the type II family, $2 \alpha$ and $2 \beta$, act by introducing double strand DNA breaks and, although they have similar enzymatic activities in vitro, have nonover-

Author contributions: P.P. designed research; P.P., M.E., and O.H. performed research; P.P., M.E., and O.H. analyzed data; P.P. wrote the paper. 
lapping functions. Topoisomerase $\| \alpha($ Top $2 \alpha)$ is required for cell viability and chromosome segregation while Top2 $\beta$ is dispensable for basic cellular functions and appears to act predominantly within the nervous system (Nitiss, 1998).

Top2 $\beta$ plays a prevalent role during mammalian nervous system maturation (McKinnon, 2016). Mice lacking the Top2 $\beta$ gene lack diaphragm motor innervation that results in perinatal lethality due to respiratory failure (Yang et al., 2000). Top2 $\beta$ mutants also exhibit defects in cortical lamination and retinal development (Lyu and Wang, 2003; Li et al., 2014). While the exact mechanism of Top2 $\beta$ action in neurons is not known, it has been implicated in regulating the transcription of subsets of genes during brain development in vivo and long genes linked to autism in cultured cortical neurons (Lyu et al., 2006; King et al., 2013). Despite the emerging role of Top2 $\beta$ in the nervous system, it remains unclear whether it has a generic function in neuronal differentiation and survival or whether it exerts unique functions in a cell-specific manner in vivo through selective regulation of key downstream targets. Recently, Top2 $\beta$ has been implicated in the transcription of activity-induced immediate early genes suggesting a highly specific and temporally regulated role for this enzyme (Madabhushi et al., 2015). In motor neurons (MNs), Top2 $\beta$ is required for neuromuscular junction (NMJ) formation at the diaphragm muscle. Despite evidence suggesting that Top $2 \beta$ regulates axon growth and neuronal survival (Tiwari et al., 2012; Li et al., 2014), the precise temporal requirement, cell specificity and function of Top2 $\beta$ in MN development remains elusive.

Besides the molecular pathways that underlie NMJ formation, proper innervation of the diaphragm muscle also requires carefully orchestrated transcriptional programs during development that regulate the specification of phrenic motor column (PMC) neurons and their guidance to the diaphragm. The establishment of PMC identity relies on the activity of Hox5 transcription factors (TFs) at cervical levels of the spinal cord (Philippidou et al., 2012). Hox proteins and their cofactors have emerged as critical early determinants of MN identity and connectivity (Philippidou and Dasen, 2013). Along the rostrocaudal axis of the spinal cord, different Hox paralogs control the specification of segmentally-restricted motor columns. At brachial levels a network of Hox proteins determines multiple aspects of lateral motor column (LMC) identity while at thoracic levels, the Hoxc9 gene is required for the emer-

P.P. is supported by grants from the National Institutes of Health (R00NS085037), Mt. Sinai Foundation, and Case Western Reserve University.

Acknowledgements: We thank Jeremy Dasen for support during the initial stages of this project and for critical comments on multiple versions of this manuscript, Steve Burden for helpful discussions and for providing Top $2 \beta-/-$ mice, and Heather Broihier, Evan Deneris, Lynn Landmesser, and Alicia Vagnozzi for comments on this manuscript.

Correspondence should be addressed to Polyxeni Philippidou at the above address, E-mail: pxp282@case.edu.

DOI:http://dx.doi.org/10.1523/ENEURO.0404-17.2017

Copyright ( $\odot 2017$ Edmond et al.

This is an open-access article distributed under the terms of the Creative Commons Attribution 4.0 International license, which permits unrestricted use, distribution and reproduction in any medium provided that the original work is properly attributed. gence of preganglionic motor column (PGC) neurons (Dasen et al., 2008; Jung et al., 2010). While individual Hox genes control the specification of distinct motor columns, they all rely on the activity of Pbx TFs for their functions. $P b x$ genes, members of the three amino acid loop extension (TALE) class of homeodomain proteins, act as cofactors for Hox proteins to establish high affinity binding to transcriptional targets (Merabet and Mann, 2016). In MNs, $P b x$ genes are required for all Hox-dependent specification programs and also play Hox-independent roles in establishing $\mathrm{MN}$ organization and topography (Hanley et al., 2016).

The critical functions of Hox/Pbx-dependent programs in MNs rely on a stringent expression pattern during development. The spatial and temporal patterns of Hox gene expression in the spinal cord are initially established though morphogen gradients and maintained through Polycomb-dependent repression mechanisms (Liu et al., 2001; Bel-Vialar et al., 2002; Golden and Dasen, 2012). $\mathrm{Pbx}$ genes also show very specific patterns of expression along the rostrocaudal axis of the spinal cord, as well as elevated expression in certain subsets of MNs (Hanley et al., 2016). While the mechanisms that control the boundaries of Hox gene expression in the spinal cord are beginning to emerge, it is less clear how high levels of $H o x$ and $P b x$ gene expression are established and maintained in specific populations of MNs.

To understand how Top2 $\beta$ controls NMJ formation and at which level of the transcriptional hierarchy that underlies $\mathrm{MN}$ development it acts, we assessed its role in $\mathrm{MN}$ specification and peripheral connectivity. Surprisingly, Top2 $\beta$ is dispensable for $\mathrm{MN}$ generation and survival, but it is differentially required for the emergence of $\mathrm{MN} \mathrm{co-}$ lumnar identities and proper innervation of peripheral muscles. In the absence of Top $2 \beta$, PMC molecular identity is lost and the majority of phrenic axons do not reach the diaphragm, while other columnar subtypes are partially preserved. We also show that Top $2 \beta$ is selectively required for the robust expression of several Hox proteins and the Hox cofactors Pbx1 and Pbx3. Finally, we show that Top $2 \beta$ mutants recapitulate many of the phenotypes observed in Pbx knockout mice such as defects in medial motor column (MMC) specification. Our results demonstrate that Top2 $\beta$ regulates MN identity in a cell-specific manner by ensuring robust activation of $\mathrm{Hox} / \mathrm{Pbx}-$ dependent transcriptional programs.

\section{Materials and Methods}

\section{Mouse genetics}

The Top2 $\beta$-/- (Yang et al., 2000) and Hb9::GFP (Arber et al., 1999; RRID:IMSR_JAX:005029) lines were generated as described. Mouse colony maintenance and handling was performed in compliance with the protocols approved by the Institutional Animal Care and Use Committee of Case Western Reserve University School of Medicine. Mice were housed in a 12/12 h light/dark cycle in cages containing no more than five animals at a time. 


\section{In situ hybridization and immunohistochemistry}

In situ hybridization and immunohistochemistry were performed as described (Philippidou et al., 2012). Wholemount GFP staining was performed as described (Philippidou et al., 2012) and motor axons were visualized in projections of confocal Z-stacks $(500-1000 \mu \mathrm{m})$. Wholemounts of diaphragm muscles from e18.5 mice were stained as described (Philippidou et al., 2012). Antibodies were generated as described (Tsuchida et al., 1994; Dasen et al., 2005; Dasen et al., 2008). Other antibodies were used as follows: rabbit anti-Top2 $\beta$ (1:500; Santa Cruz Biotechnology, RRID:AB_2205866), rabbit anti-cleaved Caspase 3 (1: 1000; Cell Signaling, RRID:AB_2341188), rabbit anti-Pbx1 (1: 2500; Cell Signaling, RRID:AB_2160295), mouse anti-olig2A488-conjugated (1:500; Millipore, RRID:AB_11205039), rabbit anti-GFP (1:1000; Invitrogen, RRID:AB_221570), goat anti-Scip (1:5000; Santa Cruz Biotechnology, RRID:AB_2268536), rabbit anti-Neurofilament (1:1000; Synaptic Systems, RRID: AB_887743), rabbit anti-Mecom (1:1000; Santa Cruz Biotechnology, RRID:AB_783296), and a-bungarotoxin, Alexa Fluor 555 conjugate (1:1000; Invitrogen, RRID:AB_2617152) . Images were obtained with a Zeiss (LSM 800) confocal microscope or a Zeiss Imager Z2 epifluorescent microscope with Apotome and analyzed with Zen Blue and ImageJ (Fiji).

\section{Experimental design and statistical analysis}

For all experiments a minimum of three embryos per genotype, both male and female, were used for all reported results. In experiments where $\mathrm{MN}$ numbers are reported, cells were counted as MNs if they expressed IsI1/2 and as LMC neurons if they expressed FoxP1. Counts were performed in the rostral brachial spinal cord, at the same rostrocaudal levels for both control and mutant animals. The $\mathrm{MN}$ numbers reported are either the average $(\mathrm{Is} \mid 1 / 2+$, FoxP1+) or the total (Scip +$)$ of three to four consecutive sections separated by $160 \mu \mathrm{m}$. For the quantitation of Scip, FoxP1, Hox, and Pbx protein levels, the fluorescence intensity in MNs in the ventral spinal cord along three to four consecutive sections was measured in ImageJ (Fiji) and the average fluorescence for each protein was then calculated. Average fluorescent intensity for control protein levels was set to 1 , and protein levels in the mutant were expressed as a fraction of control levels. P-values were calculated using paired, two-tailed Student's $t$ test.

\section{Results}

\section{Expression of Top2 $\beta$ during $\mathrm{MN}$ genesis}

To establish the temporal requirement for Top2 $\beta$ in $M N$ development we examined the time course of Top2 $\beta$ protein expression in mouse embryonic spinal cord. Consistent with a role of Top2 $\beta$ in postmitotic neurons, expression of Top2 $\beta$ is markedly elevated as MNs exit the cell cycle and begin to migrate. Top2 $\beta$ expression is detected at low levels in the olig2 ${ }^{+} \mathrm{MN}$ progenitor domain and increases as MNs differentiate and move away from the ventricular zone (Fig. 1A,B). At embryonic day 11.5 (e11.5), a time when the majority of MNs have already exited the cell cycle (De Marco Garcia and Jessell, 2008), there are increased levels of Top2 $\beta$ expression in the ventral spinal cord coinciding with Is|1/2 expression, a marker for postmitotic MNs, as compared to surrounding non-MN cells (Fig. 1B,C). Elevated Top2 $\beta$ expression is uniform along rostrocaudal levels of the spinal cord and is maintained, both in brachial and thoracic MNs, as MN axons navigate to the periphery (Fig. $1 D, F)$. Top2 $\beta$ expression persists in all Isl1/2+ MNs at late embryonic stages (e14.5), after most motor axons have already reached their final targets and initiated branching (Fig. 1C).

\section{Top2 $\beta$ is dispensable for $\mathrm{MN}$ generation and survival}

Top2 $\beta$ mutant mice show lack of diaphragm innervation and die at birth due to respiratory failure, but the mechanisms of Top2 $\beta$ action in MNs are not known (Yang et al., 2000). To determine the role of Top2 $\beta$ in MN development, we analyzed mice lacking Top $2 \beta$. We confirmed lack of Top2 $\beta$ expression by antibody staining in the spinal cord (Fig. 2A). Consistent with low levels of Top2 $\beta$ expression in progenitor cells in the spinal cord, we found that the number and location of $\mathrm{MN}$ progenitors in Top2 $\beta-/-$ mice at e11.5 was similar to control embryos as assessed by expression of the TF Olig2 (Fig. 2B). Since Top2 $\beta$ has been implicated in neuronal survival (Tiwari et al., 2012; Li et al., 2014), we initially compared MN numbers in control and Top2 $\beta-/-$ mice. We counted Isl1/ $2+$-expressing $\mathrm{MNs}$ in the ventral spinal cord at brachial levels (C3-C8) at multiple embryonic stages and we did not observe a reduction in $\mathrm{MN}$ numbers in Top2 $\beta$-/- mice (Fig. 2C). Expression of vesicular acetylcholine transporter (Vacht), as detected by in situ hybridization, also revealed similar numbers of cholinergic MNs in control and Top2 $\beta$ mutant mice (Fig. 2D). In neurons cultured from Top2 $\beta-/-$ mutants, upregulation of the neurotrophin receptor p75 has been associated with premature cell death (Tiwari et al., 2012). We therefore compared levels of p75 expression in MNs in control and Top2 $\beta-/-$ mice and saw no significant differences, suggesting that the effects of Top2 $\beta$ deletion on gene expression and neuronal phenotype are likely to be cell-type dependent (Fig. 2E). In addition, we did not detect an increase in apoptotic cells containing activated caspase 3 in the brachial and thoracic spinal cord of Top $2 \beta-/$ - mice at any stage examined (Fig. $2 F-H)$. Our results demonstrate that Top2 $\beta$ is not required for $\mathrm{MN}$ generation or survival and that the perinatal lethality and MN defects seen in Top $2 \beta-/-$ mice are not due to $\mathrm{MN}$ cell death.

To further test that initial specification of MNs proceeds normally in the absence of Top $2 \beta$, we examined the expression of the early postmitotic TFs Lhx3, Isl1/2, and $\mathrm{Hb} 9$, which collectively label the entire MN population. Expression patterns of these TFs were similar in control and Top $2 \beta-/-$ embryos at e11.5, indicating that dorsoventral patterning and signaling pathways that dictate generic aspects of MN identity are unperturbed. However, we noticed that $\mathrm{MNs}$ expressing these markers did not occupy their stereotypical positions in Top2 $\beta-/-$ mice (Fig. $21)$. The inability of MNs to adopt their correct position could reflect defects in their subtype specification. Therefore, we examined whether MNs acquire their correct subtype identities in the absence of Top2 $\beta$. Since 
a

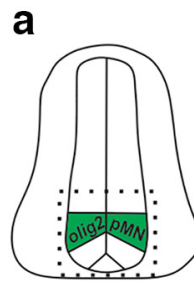

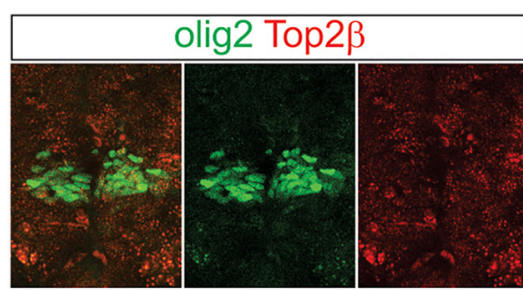

Brachial

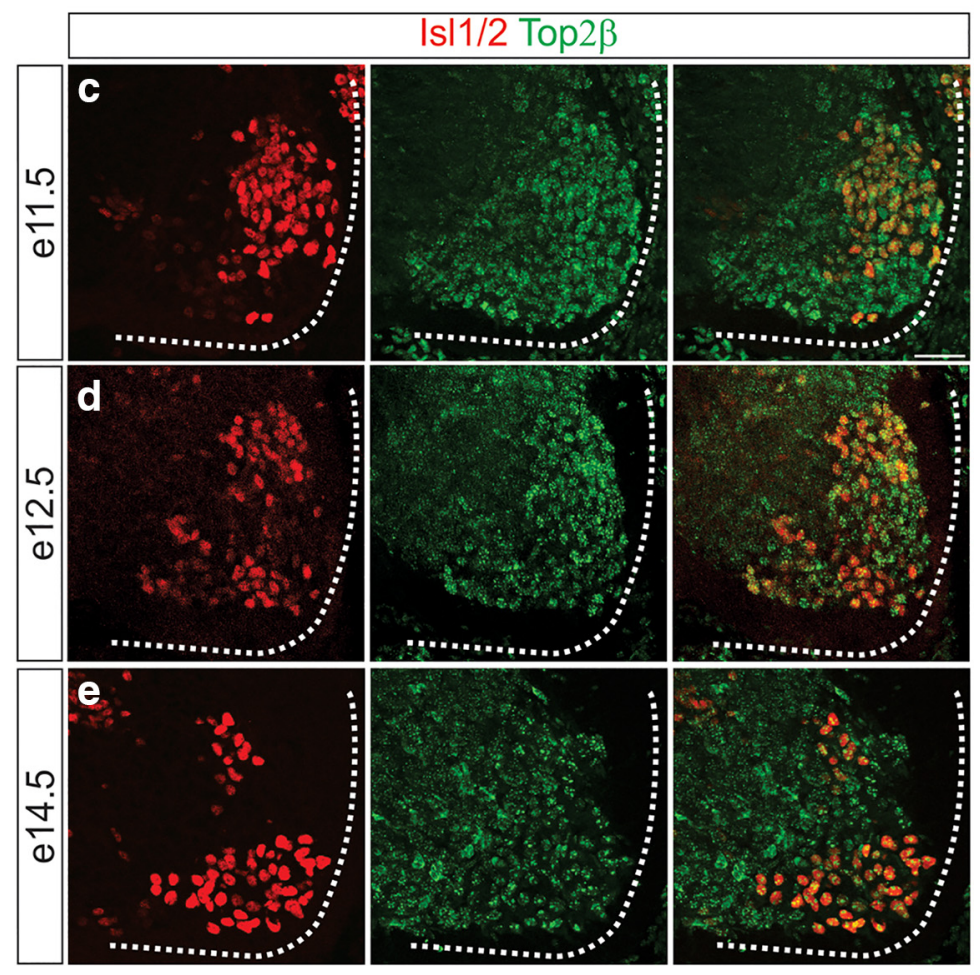

Thoracic

Is|1/2 Top $2 \beta$

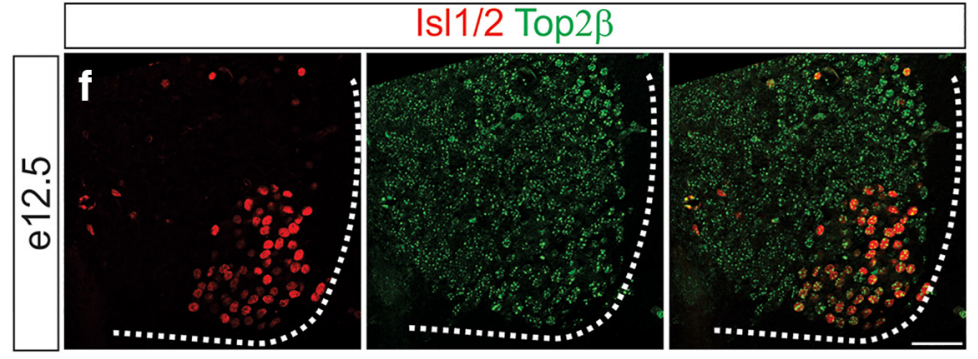

Figure 1. Top2 $\beta$ is expressed at high levels in postmitotic MNs. $\boldsymbol{A}, \boldsymbol{B}$, Low Top2 $\beta$ expression in MN progenitors (olig2 + ) at e11.5 (A) as compared to the lateral spinal cord where postmitotic MNs are located $(\boldsymbol{B})$. $\boldsymbol{C}-\boldsymbol{E}$, Top2 $\beta$ is upregulated in postmitotic MNs at brachial levels at e11.5 $(\boldsymbol{C})$, continues to be expressed as MNs navigate to their targets $(\mathrm{e} 12.5 ; \boldsymbol{D})$ and high levels of expression are maintained until later stages of MN development (e14.5; $\boldsymbol{E})$. $\boldsymbol{F}$, Top2 $\beta$ expression in MNs at e12.5 at thoracic spinal cord levels. Scale bar $=50 \mu \mathrm{m}$.

Top2 $\beta$-/- mice die from respiratory failure due to lack of diaphragm innervation (Yang et al., 2000), we first examined whether they exhibit defects in PMC specification.

\section{Erosion of PMC identity in Top2 $\beta$-/- mice}

To determine whether phrenic MN specification is impaired in Top $2 \beta-/-$ mice, we examined the expression and distribution of the POU domain TF Scip, which marks
PMC neurons at rostral cervical levels. At e11.5, MNs expressing high levels of Scip can be readily seen in the cervical spinal cord of both control and Top2 $\beta-/-$ embryos. However, while these MNs are beginning to cluster in control embryos, they are dispersed in Top $2 \beta-/-$ mice (Fig. 3A). At later embryonic stages scattered Scip+ MNs persist in Top $2 \beta-/-$ embryos; however, they are randomly distributed and express lower levels of Scip than phrenic 

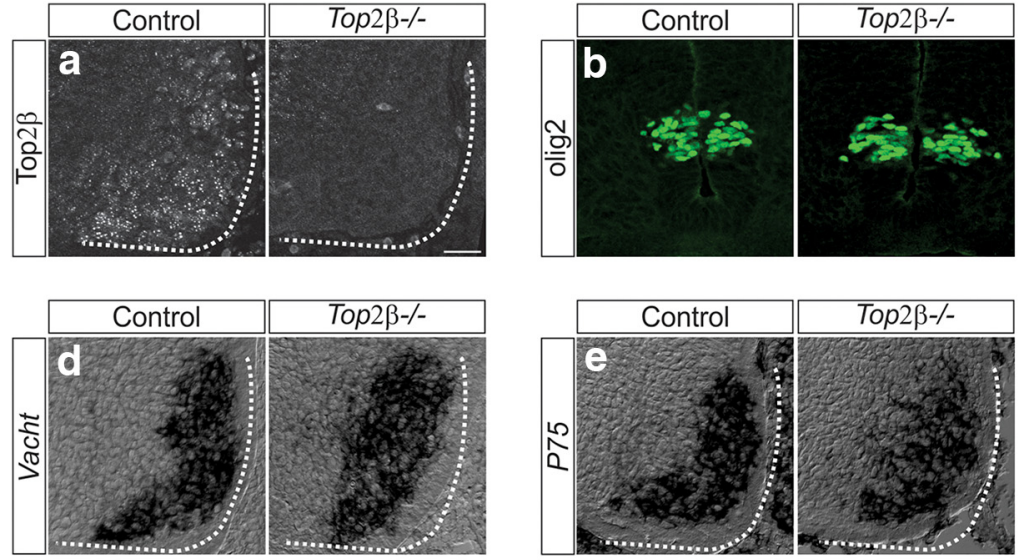

C
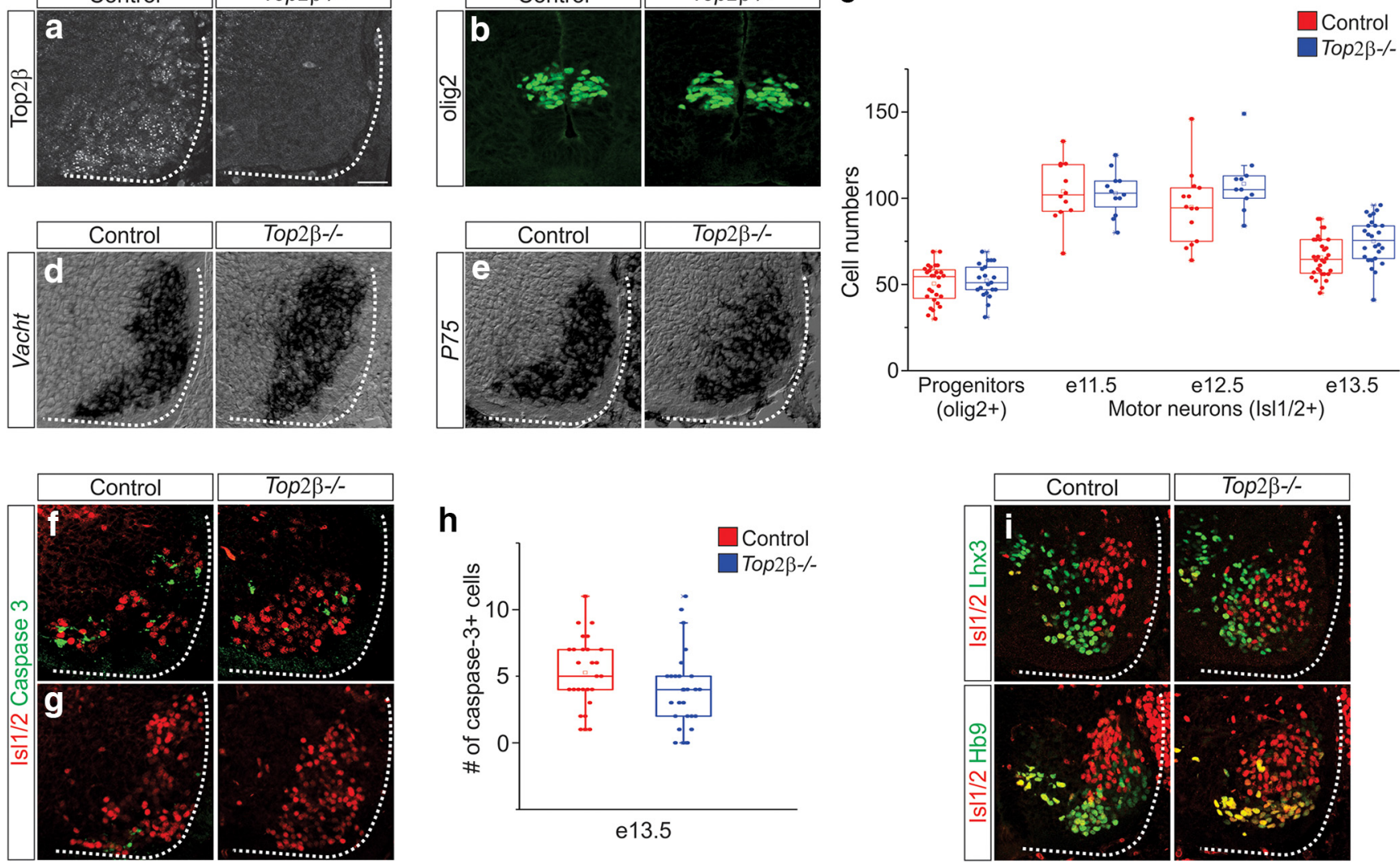

Figure 2. Top2 $\beta$ is not required for MN generation or survival. $\boldsymbol{A}$, Top2 $\beta$ protein is not detected in Top2 $\beta-/-$ mice. $\boldsymbol{B}$, MN progenitors are unchanged in Top2 $\beta-/-$ mice at $\mathrm{e} 11.5$, as seen by staining against the MN progenitor marker olig2. $\boldsymbol{C}$, Quantitation of MN progenitors (olig2+; $p=0.27$ ) and postmitotic MNs (Isl1/2+) at brachial levels of the spinal cord (C3-C8) in control and Top2 $\beta-/-m i c e$ at various time points during development (e11.5; $p=0.87$, e12.5; $p=0.2$, e13.5; $p=0.02)$. $\boldsymbol{D}$, In situ hybridization against Vacht reveals similar numbers of cholinergic MNs in control and Top2 $\beta-/-$ mice at e12.5. $\boldsymbol{E}$, Similar levels of p75 expression in control and Top2 $\beta$ mutant mice at e13.5. F, G, Activated caspase 3 staining at e13.5 (brachial levels; $\boldsymbol{F}$ ) and e12.5 (thoracic levels; $\mathbf{G}$ ) does not show an increase in apoptotic cells in Top $2 \beta$-/- mice. $\boldsymbol{H}$, Quantitation of apoptotic cells in control and Top2 $\beta$ mutant mice at e13.5 $(p=0.1)$. I, Staining against the TFs Lhx3, Isl1/2, and Hb9 that collectively mark all MNs demonstrates a disorganization of MN populations in Top2 $\beta-/-$ mice at e11.5. Scale bar $=50 \mu \mathrm{m}$.

MNs in control animals (Fig. $3 A-C)$. To determine whether the lack of clustered, highly expressing Scip MNs reflects the loss of bona fide phrenic MNs, we examined the expression of several known phrenic MN markers (Philippidou et al., 2012; Machado et al., 2014). In Top2 $\beta$-/- mice we observed a complete loss of ALCAM, pcdh10, and PTN expression from the cervical spinal cord at e12.5, indicating that the specification of phrenic MNs is disrupted (Fig. 3D-F).

To determine whether these changes at the level of the spinal cord lead to alterations in PMC peripheral projections, we examined the trajectory of phrenic axons by wholemount embryo staining. We crossed Hb9::GFP mice, expressing GFP in all MNs, to Top2 $\beta$ mutants to visualize $\mathrm{MN}$ axons. We observed a dramatic decrease in both the thickness of the phrenic nerve and terminal branching in Top2 $\beta$-/- embryos at e12.5 and e14.5 (Fig. $4 A, B)$. Wholemount muscle staining at e16.5 confirmed the lack of diaphragm innervation in Top2 $\beta-/-$ mice as previously reported (Fig. 4C; Yang et al., 2000). This defect is likely to be a consequence of the loss of PMC identity, rather than a change in the capacity of MNs to form NMJs. Consistent with this hypothesis, axons that reach the diaphragm in Top $2 \beta-/-$ embryos are able to initiate synapse formation and acetylcholine receptor clustering (Fig. 4D). Similarly, intercostal muscles that also participate in respiration are normally innervated in Top $2 \beta-/$ - mice (Fig. $4 E$ ), indicating that mutation of Top2 $\beta$ has distinct effects on PMC identity. Our data suggest that lack of Top2 $\beta$ leads to changes in the specification of distinct $\mathrm{MN}$ subtypes, rather than affecting features common to all MNs. To test this hypothesis, we next examined the specification of limb-innervating LMC neurons in Top2 $\beta$-/- mice.

\section{Defects in MN columnar and pool identities and peripheral connectivity in Top2 $\beta$ mutants}

A critical step in the specification of LMC neurons at brachial and lumbar levels of the spinal cord is the induction of the TF FoxP1. We therefore examined the expression profile of FoxP1 in the brachial spinal cord at different developmental time points. Both the number of FoxP1expressing cells and the levels of FoxP1 protein in MNs are reduced in Top $2 \beta$ mutants (Fig. $5 A-E$ ). Interestingly, 


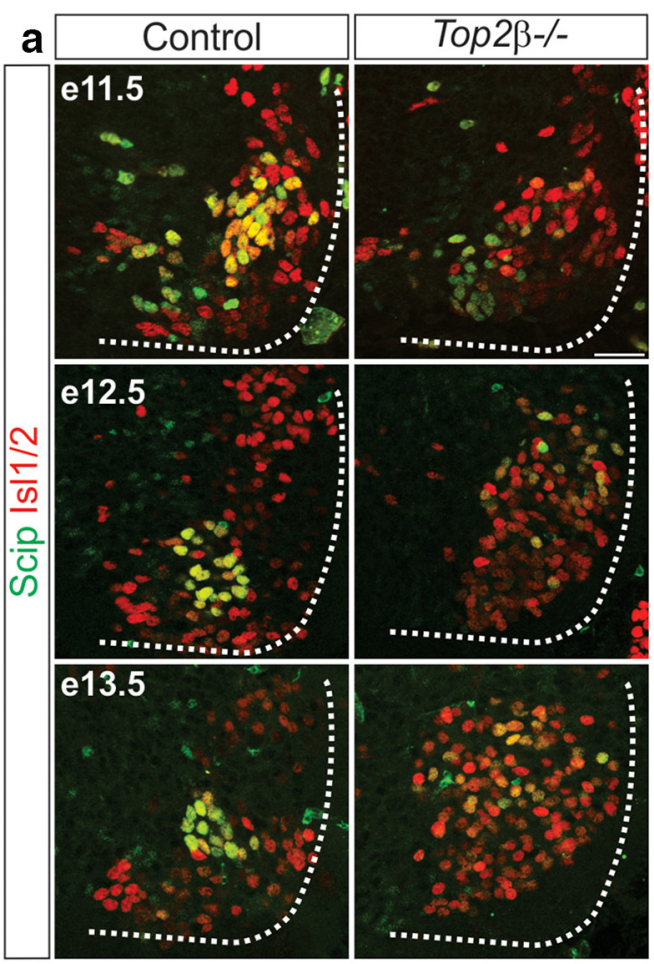

b

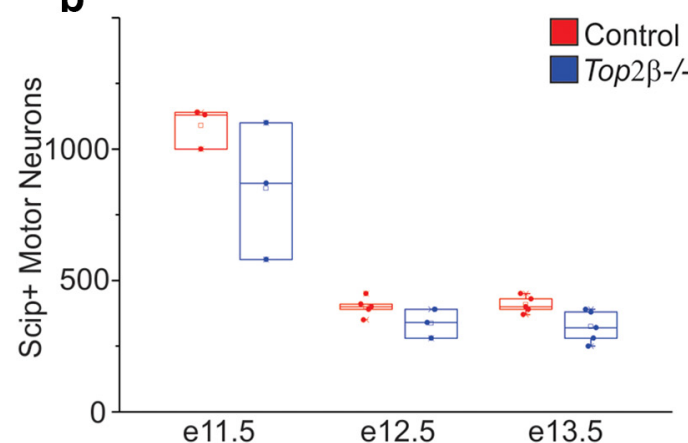

C
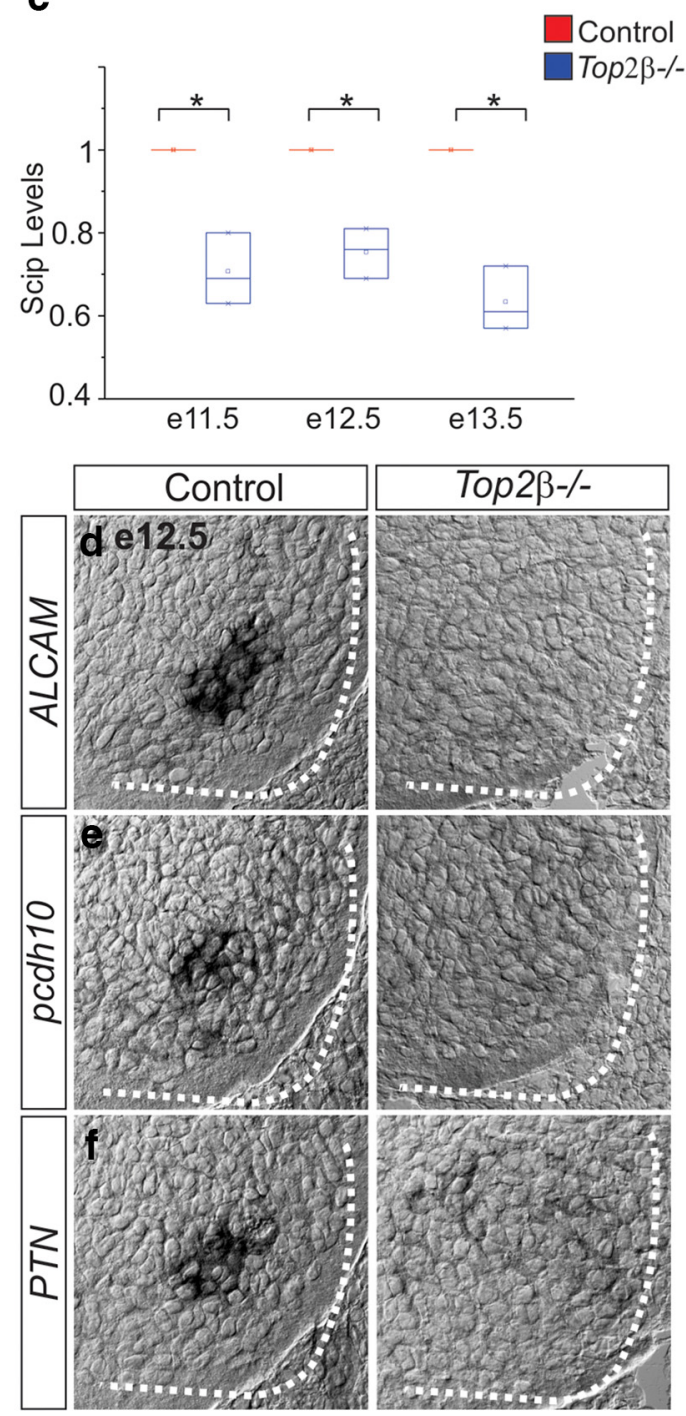

Figure 3. Erosion of PMC identity in Top $2 \beta$-/- mice. A, Scip and Isl1/2 expression in the cervical spinal cord in control and Top2 $\beta$-/mice at various time points during development. Scale bar $=50 \mu \mathrm{m}$. $\boldsymbol{B}, \boldsymbol{C}$, Quantitation of Scip-expressing MNs $(\boldsymbol{B})$ and Scip protein levels $(\boldsymbol{C})$ in the cervical spinal cord in control and Top2 $\beta-/-$ mice (see Materials and Methods for quantitation methods). $\boldsymbol{D}-\boldsymbol{F}$, Expression of PMC-specific genes ALCAM (D), pcdh10 (E), and PTN $(\boldsymbol{F})$ is abolished in Top2 $\beta$-/- embryos at e12.5.

unlike the disorganization of PMC neurons, the domain of expression of FoxP1 appears to be initially similar between control and Top2 $\beta$ mutant embryos as lowexpressing FoxP1 neurons occupy the stereotypical LMC position. This raises the possibility that distinct MN columns are differentially impacted in Top $2 \beta$ mutants.

At limb levels, FoxP1 in LMC neurons induces the expression of the retinoic acid (RA) synthetic enzyme Raldh2. Despite low FoxP1 levels in Top2 $\beta$ mutants, we still observe Raldh2 induction, although at lower levels and more diffusely in the ventral spinal cord (Fig. 5F). This further supports the idea that unlike PMC neurons, some features of LMC identity are preserved. To further examine LMC specification we investigated whether the specification of MN pools, clustered groups of MNs innervating the same muscle targets, was affected in Top $2 \beta$ mutants. At brachial levels of the spinal cord MNs projecting along the median and ulnar nerves express high levels of the TF Scip while MNs projecting to the cutaneous maximus (CM) and latissimus dorsi (LD) muscles express the TF Pea3. In Top2 $\beta$ mutant mice both Scip and Pea3 are dramatically downregulated and the remaining $\mathrm{MNs}$ expressing either TF are no longer clustered (Fig. 5G,H). Our results indicate that while brachial LMC neurons retain some features of their columnar identity, pool identities are more severely affected in Top $2 \beta$ mutant mice.

To assess the effects of the Top2 $\beta$ mutation on $\mathrm{MN}$ axonal trajectories, we examined limb innervation by wholemount immunofluorescence. In FoxP1-/- mice, peripheral patterns of innervation are preserved despite the erosion of MN identity and the absence of pool marker expression (Dasen et al., 2008). In Top2 $\beta$-/- mice however we observed distinct changes to peripheral innervation patterns. Consistent with a loss of Pea3, we found a 

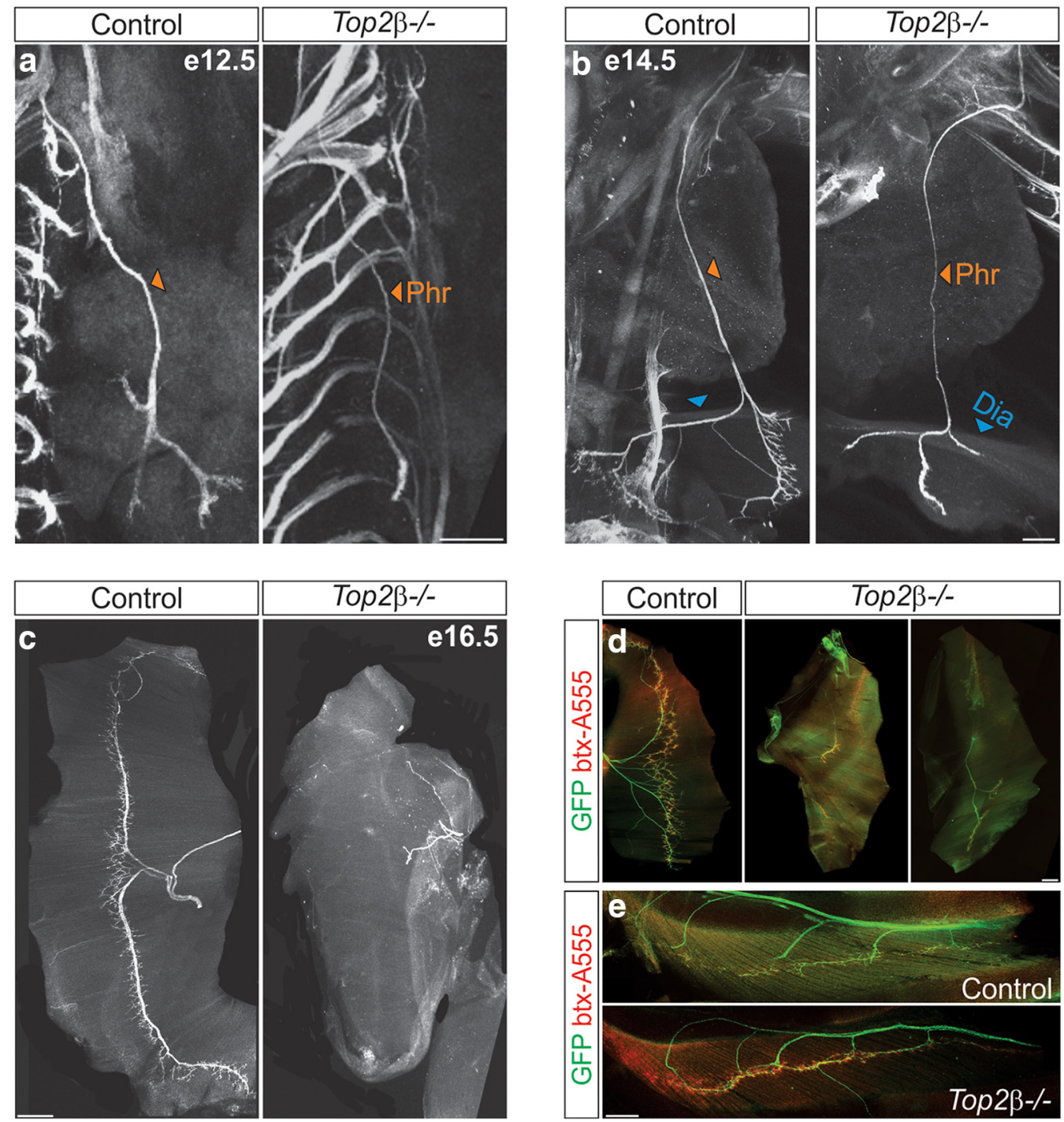

Figure 4. Defects in PMC peripheral connectivity in Top2 $\beta$-/- mice. $\boldsymbol{A}$, B, Wholemount staining of Top2 $\beta$-/-;Hb9::GFP embryos at e12.5 and e14.5 shows that the phrenic nerve is thinner in mutant mice and does not branch at the diaphragm muscle as compared to control animals. Phr, phrenic nerve; Dia, diaphragm muscle. Scale bar $=200 \mu \mathrm{m}$. $\boldsymbol{C}$, Lack of diaphragm innervation in Top2 $\beta-/-$ embryos at e16.5. Scale bar $=500 \mu \mathrm{m}$. $\boldsymbol{D}$, Lack of diaphragm innervation in Top2 $\beta-/-$ embryos (right panels) as compared to controls (left panel) at e18.5. Motor axons that reach the diaphragm in Top2 $\beta$-/- embryos initiate synapse formation and cluster postsynaptic acetylcholine receptors. Scale bar $=500 \mu \mathrm{m}$. E, Intercostal muscles show normal innervation in Top2 $\beta-/-$ mice. Btx-A555, bungarotoxin-Alexa Fluor 555. Scale bar $=200 \mu \mathrm{m}$.

dramatic reduction in CM innervation (Fig. $5 /, J$ ). In contrast, and despite the loss of Scip expression, we surprisingly saw a $70 \%$ increase in the thickness of both the ulnar and median nerves in Top2 $\beta-/-$ mice at e12.5, accompanied with a loss of branching at target muscles. Similar changes were also seen for the radial nerve $(51 \%$ increase) indicating that the three major limb-innervating motor nerves are impacted in a similar manner. The increase in nerve thickness is likely a result of a rerouting of all MNs along these 3 major tracts. Consistent with this idea we observe a loss of proximal motor nerves, such as the axillary and lateral pectoral nerves, in Top2 $\beta$-/- mice (Fig. $5 /, \mathcal{~}$. Our data suggest that in the absence of motor pool specification programs MNs revert to a rudimentary projection pattern along major nerve tracts.
Since all MNs express high levels of Top2 $\beta$, we next tested whether columnar specification is impaired at all levels of the spinal cord in Top2 $\beta-/-$ mice. At thoracic levels of the spinal cord, PGC neurons projecting to sympathetic chain ganglia (scg) are defined by low levels of FoxP1 and neuronal nitric oxide synthase (nNOS) expression (Fig. 6A). In Top2 $\beta$ mutants, PGC FoxP1 ${ }^{+}$neurons are not found in their typical position and nNOS expression is greatly reduced (Fig. $6 B, C$ ). The remaining nNOSexpressing neurons are displaced in more ventral positions in the spinal cord. Our results demonstrate that multiple columnar specification programs are affected in Top2 $\beta$-/- mice.

At thoracic levels of the spinal cord PGC neurons innervate neurons along the sympathetic chain (scg). De- 

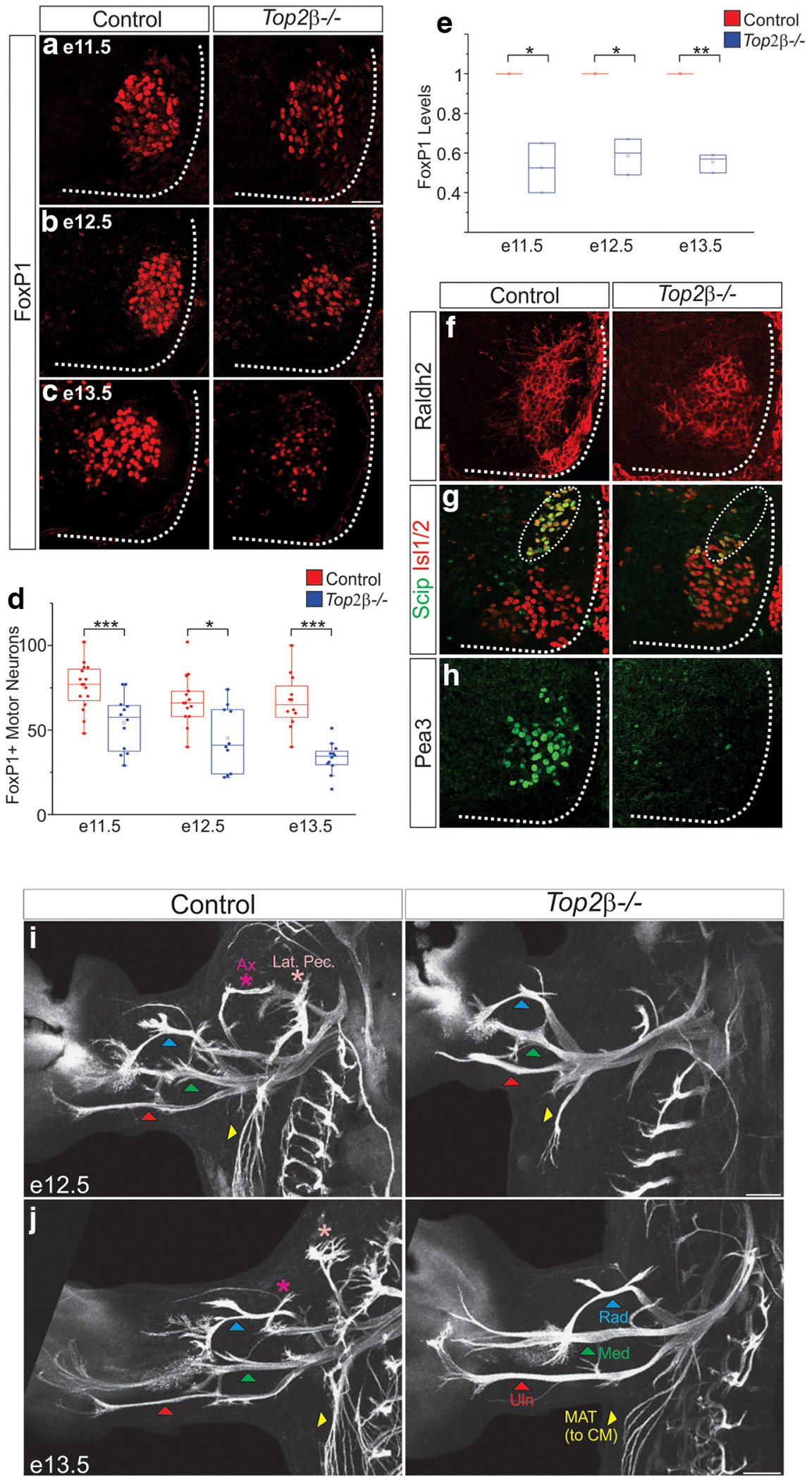

Figure 5. Defects in LMC columnar, pool identities, and peripheral projections in Top2 $\beta-/-$ mice. $\boldsymbol{A}$ - $\boldsymbol{C}$, Reduction in FoxP1 levels in the brachial spinal cord of Top2 $\beta$-/- embryos at e11.5 (A), e12.5 (B), and e13.5 (C). Scale bar = $50 \mu \mathrm{m}$. $\boldsymbol{D}$, Quantitation of FoxP1-expressing MNs in the brachial spinal cord in control and Top2 $\beta$-/- mice at various time points during development (e11.5; $p$ $=0.0002$, e12.5; $p=0.012$, e13.5; $\left.p=2.85 \times 10^{-5}\right)$. $\boldsymbol{E}$, Quantitation of FoxP1 protein levels in the brachial spinal cord in control and Top2 $\beta$-/- mice (e11.5; $p=0.02$, e12.5; $p=0.01$, e13.5; $p=0.004)$. $\boldsymbol{F}$, Expression of Raldh2 persists but is diffuse in Top2 $\beta$-/- embryos 
continued

at e12.5. G, $\boldsymbol{H}$, The expression of pool-specific markers Scip $(\boldsymbol{G})$ and Pea3 $(\boldsymbol{H})$ is eliminated in Top2 $\beta$-/- embryos at e12.5. $\boldsymbol{I}$, $\boldsymbol{J}$, Limb MNs project to the periphery but stay along the three major nerve branches and fail to innervate individual muscles in Top2 $\beta$-/- mice at e12.5 (I) and e13.5 (J). Projections along proximal nerves are lost in the mutants. Ax, axillary; Lat. Pec., lateral pectoral; Rad, radial; Med, median; Uln, ulnar; MAT, medial anterior thoracic (projecting to CM muscle). Scale bar $=200 \mu \mathrm{m}$.

spite a decrease in the expression of PGC markers and displacement of their cell bodies in Top $2 \beta-/-$ mice, projections to the scg appear to be preserved, although there appears to be a defect in the arborization of PGC axon terminals (Fig. 6D). These data demonstrate that Top2 $\beta$ deletion differentially impacts the connectivity of PGC, $\mathrm{LMC}$, and PMC neurons.

\section{Top2 $\beta$ is required for the induction and maintenance of high Hox and $\mathrm{Pbx}$ protein levels}

How does Top2 $\beta$ activity contribute to the subtype specification of spinal MNs? Since the acquisition of both columnar and pool identities requires the activity of Hox TFs along the rostrocaudal axis, we examined whether removal of Top2 $\beta$ affects Hox and Hox cofactor protein expression. We first assessed the expression of Hox proteins known to have an instrumental role in MN columnar specification: Hoxa5 for PMC, Hoxc6, and Hoxc8 for brachial LMC and Hoxc9 for PGC. In the absence of Top2 $\beta$, the rostrocaudal boundaries of Hox protein expression are preserved, indicating that $\mathrm{MN}$ defects are not due to altered Hox protein spatial distribution (Fig. 7A-D). We did however observe variable differences in the levels of expression of each Hox protein at e11.5; Hoxc6 and Hoxc8 were attenuated in the brachial spinal cord and high Hoxc9 expression was not seen in presumptive PGC neurons, suggesting that low levels of Hoxc9 may contribute to misspecification of these neurons as previously described (Figs. 7E-H, 8G ; Jung et al., 2010). Low levels of Hoxc6 and Hoxc8 likely contribute to the columnar and pool specification defects seen in Top $2 \beta$-/- mice. Surprisingly, levels of Hoxa5, the major Hox determinant of PMC identity, were unchanged indicating that the absence of phrenic MNs is not a result of decreased Hoxa5 activity and that Top $2 \beta$ potentially regulates additional PMC determinants.

$\mathrm{Pbx} 1$ and $\mathrm{Pbx} 3$ are critical cofactors for Hox proteins and are required for PMC specification (Hanley et al., 2016). In Top2 $\beta$ mutants, we find that levels of both Pbx1 and $\mathrm{Pbx} 3$ are greatly reduced at $\mathrm{e} 11.5$ and this loss was observed at all rostrocaudal levels of the spinal cord (Fig. $8 A-G)$. This more widespread downregulation suggests
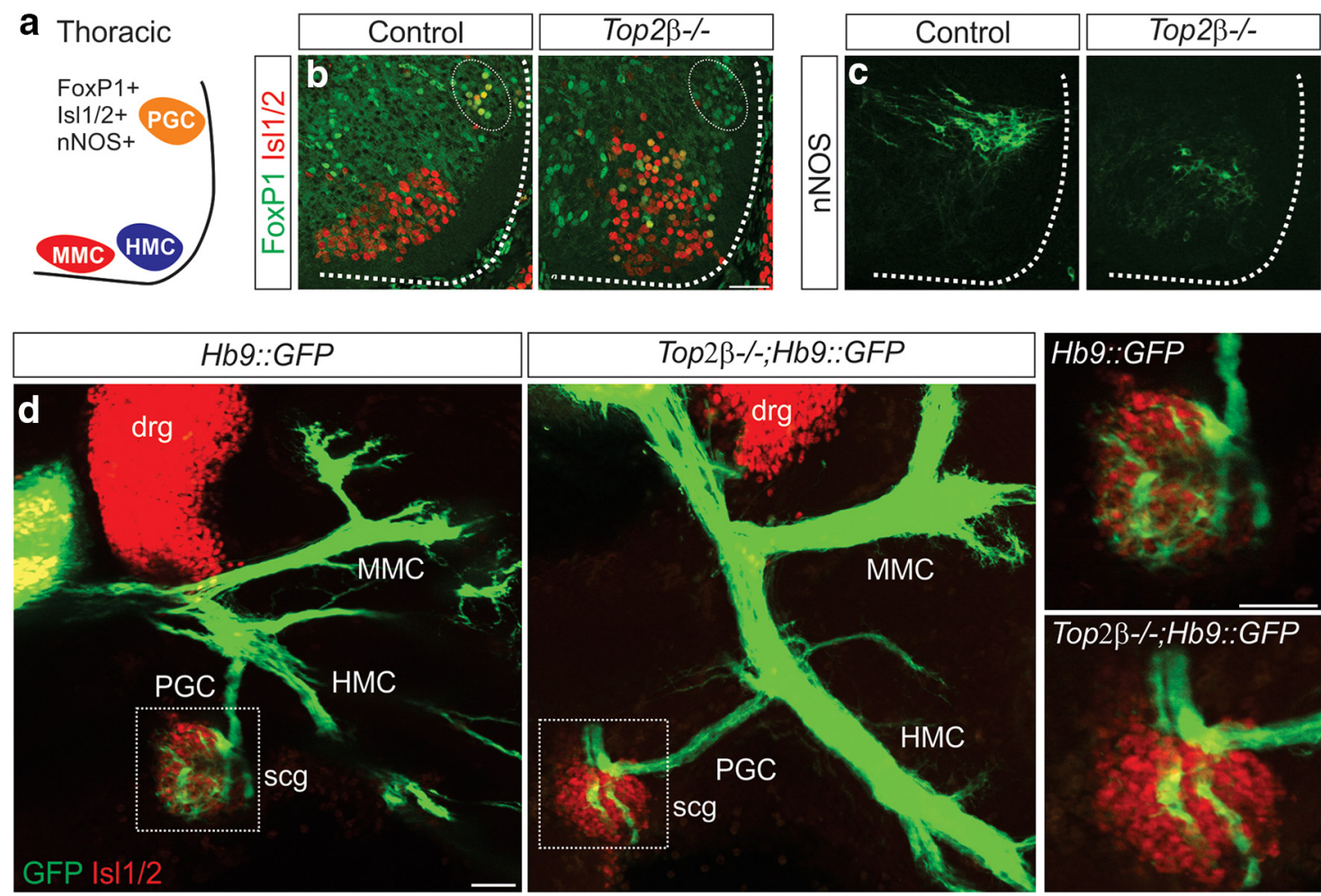

Figure 6. Defects in PGC columnar identities and peripheral projections in Top $2 \beta-/-$ mice. $\boldsymbol{A}$, Organization of motor columns at thoracic levels of the spinal cord; PGC, preganglionic motor column, MMC, medial motor column, HMC, hypaxial motor column. $\boldsymbol{B}$, $\boldsymbol{C}$, Expression of PGC markers FoxP1 (white circle; $\boldsymbol{B}$ ) and nNOS $(\boldsymbol{C})$ is dramatically reduced in Top $2 \beta-/-$ embryos. The remaining neurons expressing nNOS are displaced ventrally. Scale bar $=50 \mu \mathrm{m}$. $\boldsymbol{D}, \mathrm{PGC}$ neurons project to scg in Top2 $\beta-/-\mathrm{mice}$ but show an aberrant innervation pattern at the target. scg: sympathetic chain ganglia and drg: dorsal root ganglia. Scale bar $=50 \mu \mathrm{m}$. 

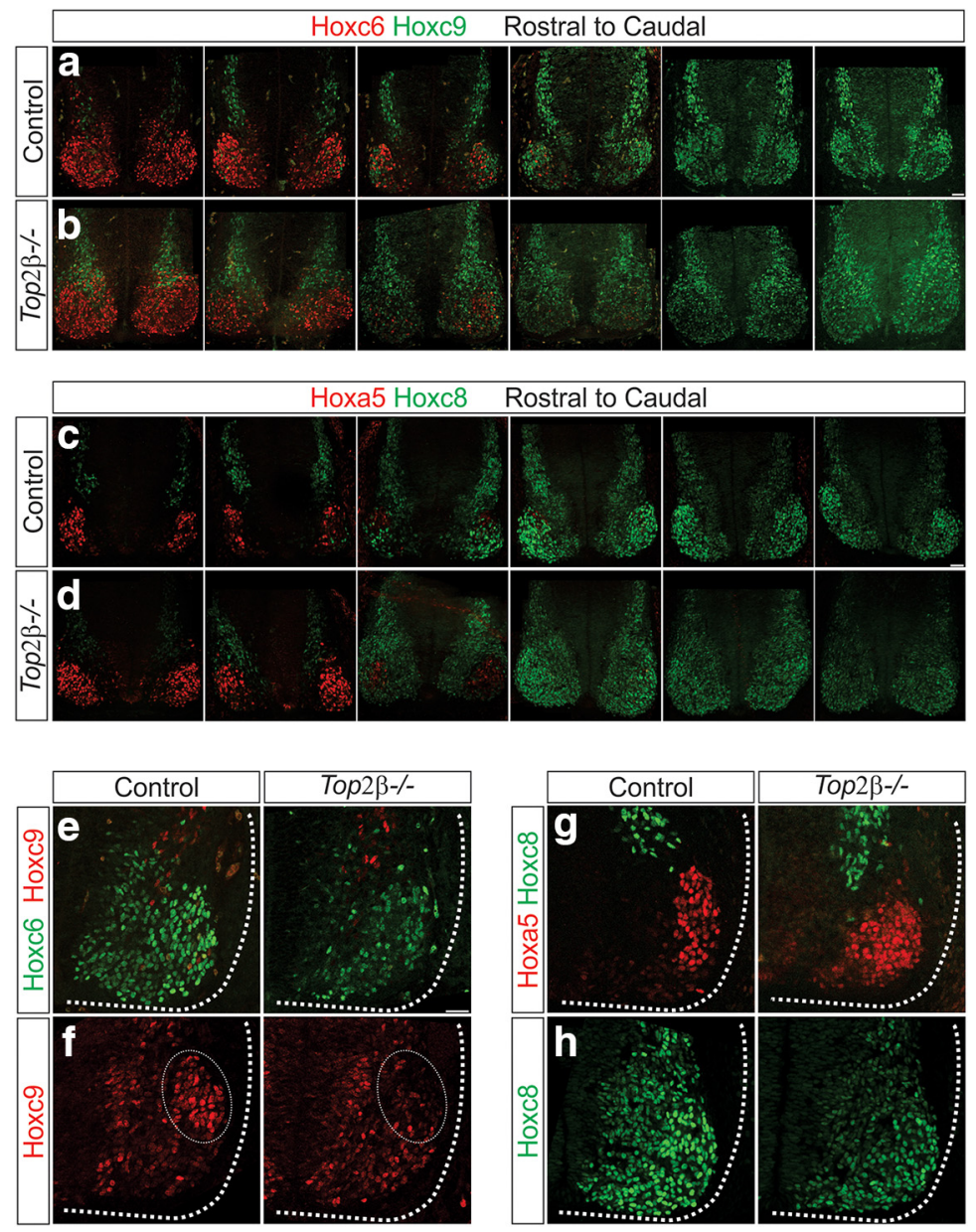

Figure 7. Reduction of Hox protein levels in Top2 $\beta-/-$ mice. $\boldsymbol{A}-\boldsymbol{D}$, The rostrocaudal expression pattern of Hox genes is preserved in Top $2 \beta-/-$ mice at e11.5. Scale bar $=50 \mu \mathrm{m}$. $\boldsymbol{E}-\boldsymbol{H}$, Hox protein expression levels in control and Top2 $\beta-/-$ mice at e11.5. Levels of Hoxc6 $(p=0.007)$, Hoxc8 $\left(p=2.4 \times 10^{-5}\right)$, and Hoxc9 $(p=0.04)$ are decreased while Hoxa5 levels $(p=0.84)$ are unchanged. Scale bar $=50 \mu \mathrm{m}$.

that $P b x$ genes function as downstream effectors of Top2 $\beta$ and that their loss may be responsible for the phenotypes observed in Top2 $\beta$-/- mice.

\section{Top2 $\beta$ controls MN organization and MMC identity}

To test whether Pbx proteins act downstream of Top2 $\beta$, we examined whether Top2 $\beta$ mutants exhibit additional defects in MN specification that are similar to those observed in $P b x$ mutants. While $P b x$ genes are required for the induction of Hox-dependent MN specification programs, they also have independent roles in MN topography and axial muscle-innervating MMC neuron development. We examined whether MNs in Top2 $\beta$ mutants exhibit similar disorganization as $\mathrm{Pbx}$ mutants. Unlike in control embryos, where MNs expressing IsI1/2 and Hb9 progressively segregate, we found that these $\mathrm{MN}$ populations were intermixed both at brachial and thoracic levels in Top2 $\beta$-/- mice (Fig. 9A-D). In Top2 $\beta$-/- embryos, Isl1/2+ MNs occupied a more medial position in the spinal cord and failed to migrate to their most dorsal positions, similar to the migration defects observed in Pbx mutants (Hanley et al., 2016).
We next examined whether MMC specification is affected in Top2 $\beta-/-$ mice. MMC neurons are found at all rostrocaudal levels of the spinal cord and their development is thought to be Hox-independent. However, MMCrestricted genes are depleted in $P b x$ mutants, indicating that $P b x$ genes play a Hox-independent role in the specification of this population (Hanley et al., 2016). We examined the expression of Mecom and lifr, two genes that require $\mathrm{Pbx}$ proteins for $\mathrm{MMC}$-restricted expression. Both of these genes were found to be downregulated in Top2 $\beta$ mutants (Fig. 9E,F). It is worth noting that not all MMCspecific gene expression is lost in Top2 $\beta$ mutants. Both the TF Lhx3 and the cytokine receptor gp130, which are highly enriched in the MMC, persist in Top2 $\beta$ mutants (Fig. 9G,H; Schaller et al., 2017). Our results indicate that Top2 $\beta$ dictates MN specification through Hox and Pbxdependent transcriptional programs.

\section{Discussion}

The acquisition of proper MN subtype identity is a critical step in the assembly of motor circuits and the execution of vital functions such as respiration and loco- 

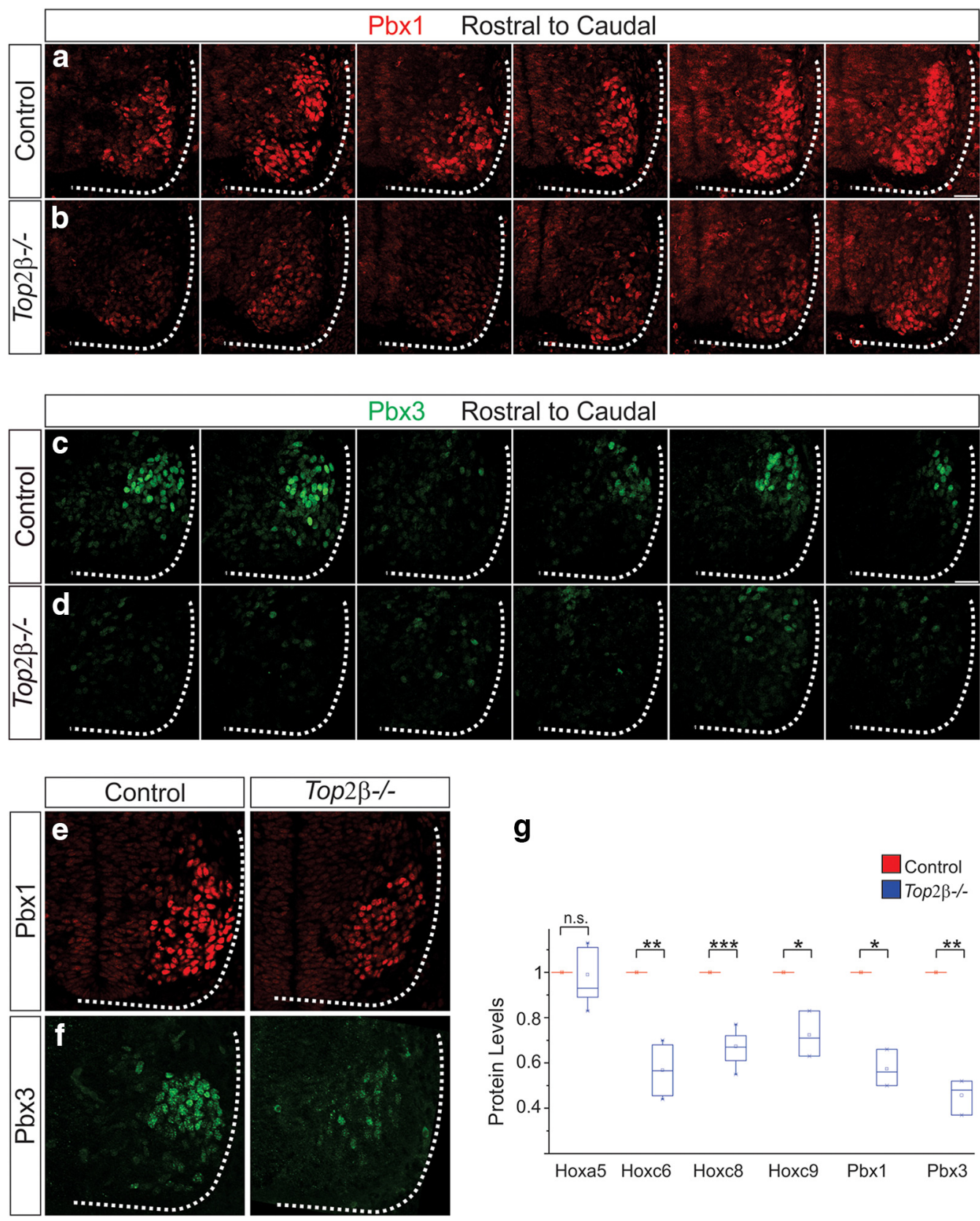

g

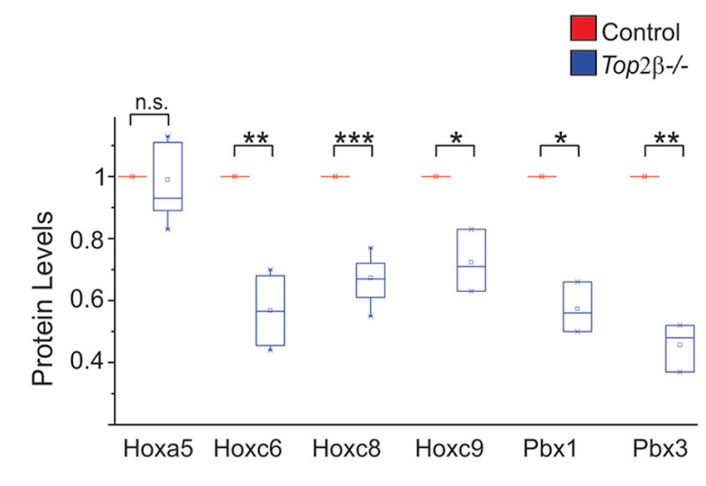

Figure 8. Reduction of Pbx protein levels in Top2 $\beta$-/- mice. A-F, Pbx protein expression levels in control and Top2 $\beta$-/- mice at e11.5. Levels of $\operatorname{Pbx} 1(p=0.01)$ and $\mathrm{Pbx} 3(p=0.007)$ are decreased at all rostrocaudal levels of the spinal cord. G, Quantitation of Hox and $\mathrm{Pbx}$ protein levels at e11.5.

motion. We found that Top2 $\beta$ plays an essential role in MN development, acting through early, subtype-specific transcriptional programs during MN columnar and pool differentiation. We discuss the role of Top2 $\beta$ in MN development and potential mechanisms of Top2 $\beta$ action.

\section{Specific functions of Top2 $\beta$ in MNs}

Type II topoisomerases solve DNA topological problems by transiently creating double strand breaks to relieve torsional stress during DNA processes such as replication and transcription. Top2 $\beta$ has been implicated in nervous system development and multiple neuronal populations are impaired in Top2 $\beta$ mutants (Lyu and
Wang, 2003; Nevin et al., 2011; Li et al., 2014). In the absence of Top $2 \beta$ mice die at birth from respiratory dysfunction due to the lack of synapses at the diaphragm but the mechanisms by which Top2 $\beta$ affects NMJ formation and the exact function of Top2 $\beta$ in MNs had not been resolved (Yang et al., 2000). We demonstrate that Top2 $\beta-/-$ phrenic MNs are not impaired in their ability to form synapses as previously thought and that Top $2 \beta$ acts early in postmitotic PMC neurons to establish specification programs. Our study points to potential mechanisms for Top2 $\beta$ involvement in neurodevelopmental disorders, not necessarily at the time of synapse formation but rather early in development as neuronal subtypes are being generated. 
Brachial
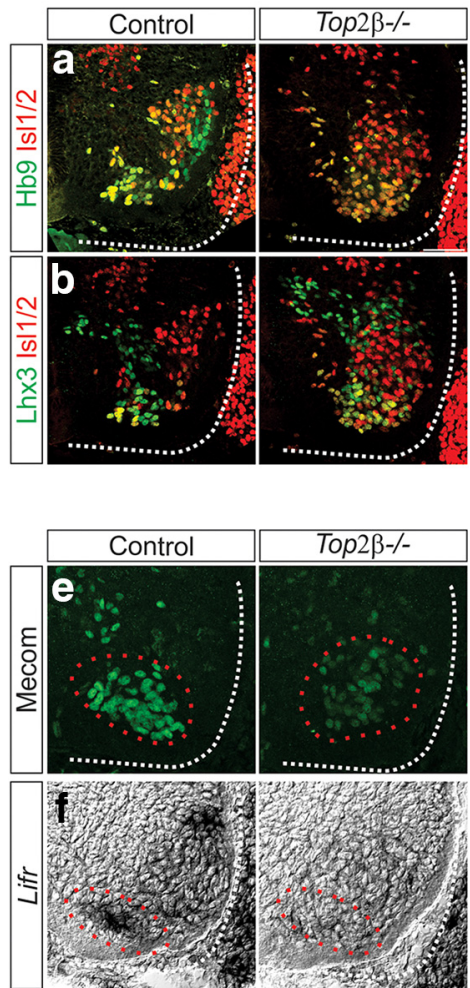

Thoracic
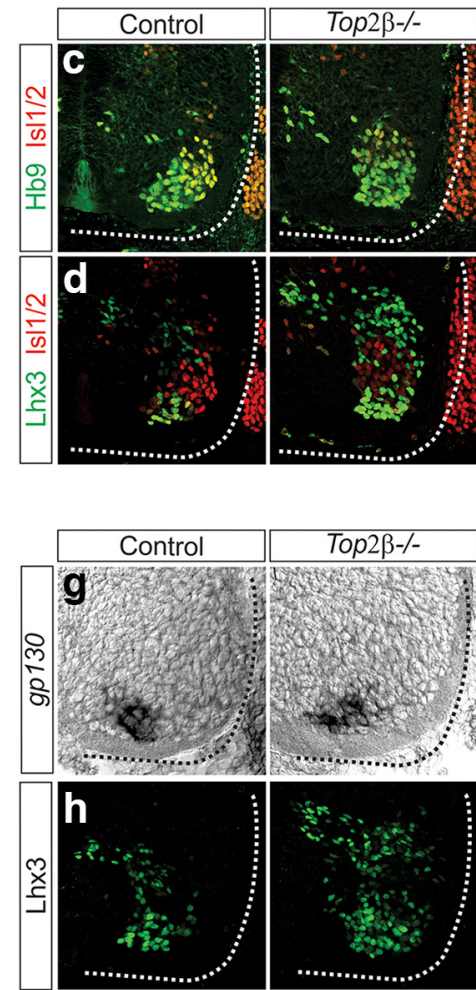

Figure 9. Defects in MN organization and MMC specification in Top2 $\beta-/-$ mice. $\boldsymbol{A}-\boldsymbol{D}$, Disorganization of MNs in Top2 $\beta-/-$ mice at e12.5 at brachial $(\boldsymbol{A}, \boldsymbol{B})$ and thoracic $(\boldsymbol{C}, \boldsymbol{D})$ levels of the spinal cord. Hb9+ and Isl1/2+ MNs do not appear to segregate in Top2 $\beta$-/- mice, similar to the phenotype observed in Pbx1/3 mutant animals. Scale bar $=50 \mu \mathrm{m}$. $\boldsymbol{E}, \boldsymbol{F}$, Effects of Top2 $\beta$ deletion on the expression of MMC molecular markers at brachial levels of the spinal cord at e12.5. Mecom and Lifr (red circles), both targets of Pbx proteins, are downregulated in Top2 $\beta$-/-mice. $\mathbf{G}, \boldsymbol{H}$, Expression of gp130 (G) and Lhx3 $(\boldsymbol{H})$ persist in Top2 $\beta$-/-mice at e12.5. Dorsal Lhx3 expression corresponds to a population of $\mathrm{V} 2$ interneurons that appears to be expanded in Top2 $\beta$-/- mice.

Pharmacological inhibition of Top2 $\beta$ in cultured neurons and deletion of Top2 $\beta$ in vivo was shown to affect survival and neurite outgrowth in multiple classes of neurons, suggesting that Top2 $\beta$ may control generic pathways active in multiple neuronal populations to promote axon growth and survival (Tiwari et al., 2012). Our data, however, indicate that Top2 $\beta$ is not required in vivo for MN survival. We do not observe an upregulation of p75 and a resulting increase in apoptosis as has been reported for other neuronal populations, indicating that Top2 $\beta$ plays distinct roles in different neuronal subtypes. In Top2 $\beta$ mutants MNs extend their axons to the periphery and grow along major tracts in the limb but subsequently fail to branch to their specific muscles. These defects in peripheral projections appear to be specific for certain classes of MNs; projections along the phrenic nerve are dramatically reduced while LMC neurons project along major nerve tracks in the limb but fail to branch to individual muscles. This specificity argues against a generic function of Top2 $\beta$ in neurite outgrowth, we rather favor the idea that Top2 $\beta$ acts during a critical window in early MN development to orchestrate the specification of MN subtypes. Our results highlight an unexpected specificity for Top2 $\beta$ function and offer support to the idea that Top2 $\beta$ disruption in the nervous system can have subtle, specific effects, manifesting for example as autism spec- trum disorders (King et al., 2013), rather than global dysfunction and wide-spread neuronal cell death.

\section{Top2 $\beta$ in the specification of columnar MN identity}

Our results indicate that Top2 $\beta$ has a critical role in the specification of MN columnar identity and in the absence of Top2 $\beta$ different MN columns are impacted with varying severity (Fig. 10). Phrenic MNs appear to be the most severely affected as Top $2 \beta$ mutants do not show induction of any phrenic-specific markers, few axons project along the phrenic nerve and diaphragm innervation is completely absent. While LMC and PGC neurons also appear disorganized, several column-specific markers, such as FoxP1 and nNOS, respectively, are partially preserved. The complete erosion of PMC identity reveals an increased sensitivity of the phrenic $\mathrm{MN}$ population to Top2 $\beta$ deletion, suggesting the specific regulation of PMC determinants by Top2 $\beta$. PMC identity is dictated by select transcriptions factors including Hox 5 proteins and their cofactors Pbx1 and Pbx3 (Philippidou et al., 2012; Hanley et al., 2016). Our data show that levels of Hoxa5 are not altered in Top2 $\beta$ mutants; however, $\mathrm{Pbx} 1$ and $\mathrm{Pbx} 3$ protein levels are reduced by $\sim 50 \%$, suggesting that $\mathrm{Pbx}$ downregulation contributes to the defects in PMC specification and connectivity. Consistent with this idea, $\mathrm{Pbx}$ mutants display defects in PMC specification 


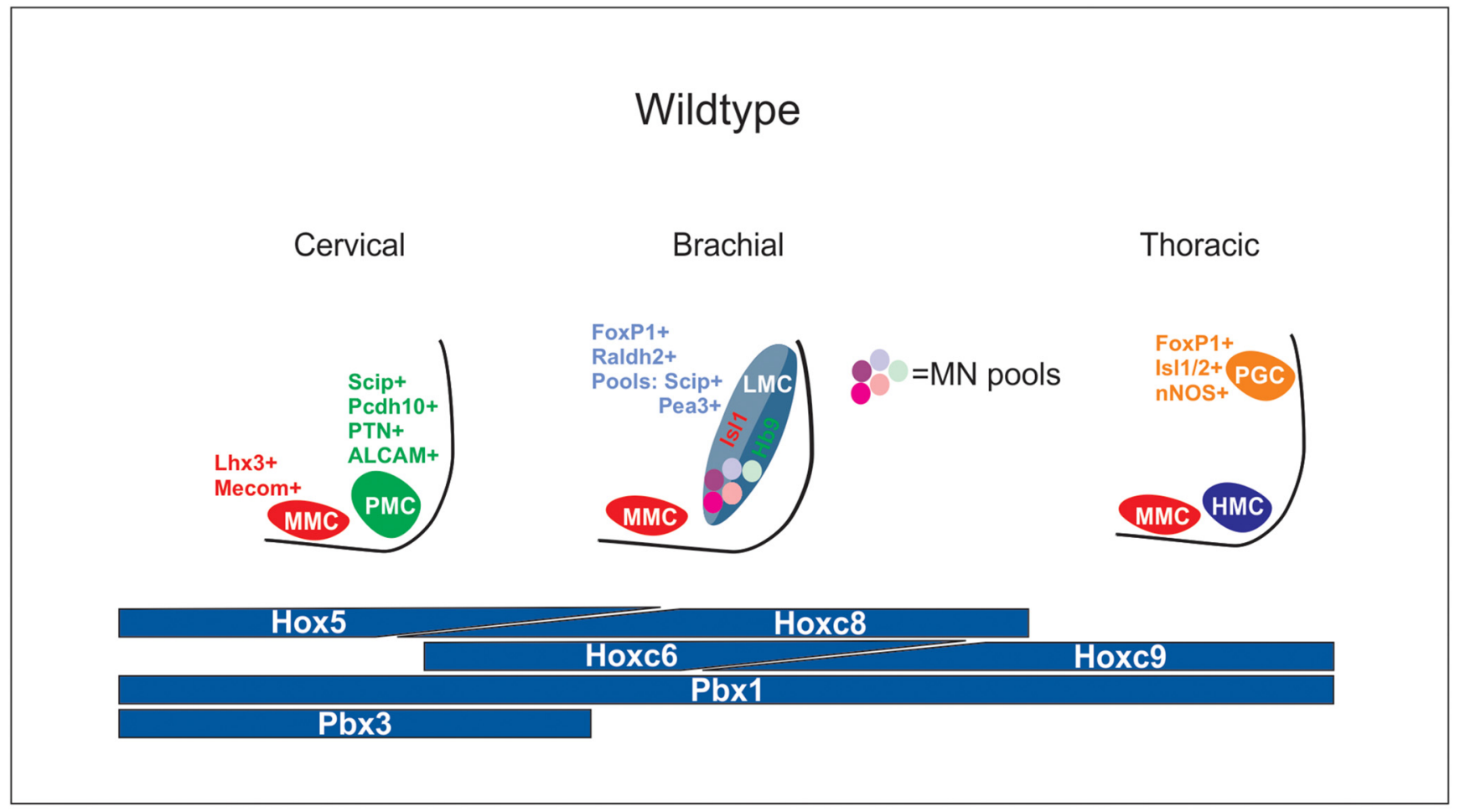

\section{Top2 $\beta-/-$}

\section{Cervical}

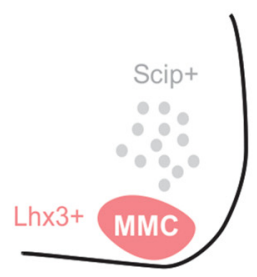

Brachial

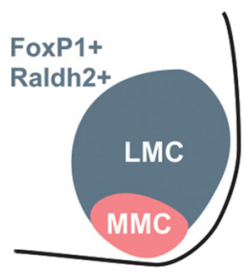

Thoracic

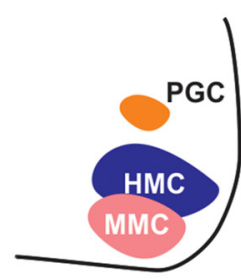

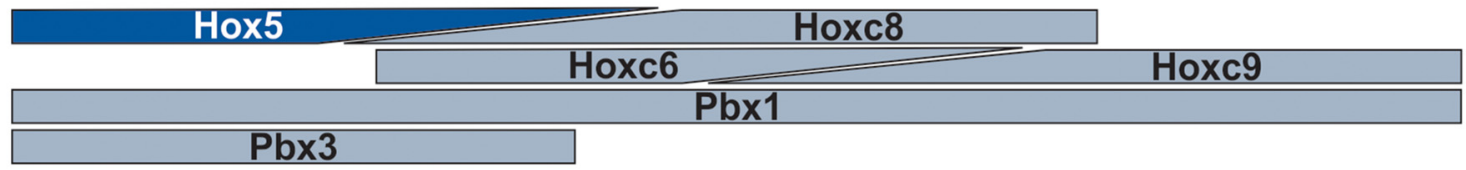

Figure 10. Top $2 \beta$ impacts multiple aspects of MN development through regulation of Hox/Pbx-dependent transcriptional programs. Top $2 \beta$ differentially controls the development of MN subtypes. In the absence of Top2 $\beta$, phrenic MNs are not specified at cervical levels of the spinal cord. At brachial levels, LMC neurons retain aspects of their columnar identity but MN pools are lost. At thoracic levels, PGC neurons become displaced and disorganized. MMC neurons, present at all levels of the spinal cord, lose expression of some of their molecular determinants and are disorganized. These defects largely recapitulate phenotypes observed in $H o x$ and $P b x$ mutant mice and the expression of multiple Hox and Pbx proteins is reduced in Top2 $\beta$-/- mice. Our results demonstrate that Top2 $\beta$ functions through the regulation of $\mathrm{Hox} / \mathrm{Pbx}$-dependent transcriptional pathways. 
and diaphragm innervation that are similar to that of Top2 $\beta$ mutants.

While $P b \times 1 / 3$ and Top $2 \beta$ mutants exhibit similar phenotypes in regards to phrenic MNs, the peripheral projections of LMC neurons are differentially affected, with Top2 $\beta$ mutants showing increased projections along major nerves while $P b \times 1 / 3$ mutants exhibit thinning of most limb-innervating axons. In Top2 $\beta$ mutants FoxP1 and Pbx expression is partially preserved, compared to a complete absence in $P b \times 1 / 3$ mutants. This difference in the levels of FoxP1 and Pbx likely contributes to the differential effects on LMC connectivity observed. Our data also reveal an increased sensitivity of PMC neurons to fluctuating Pbx levels and a potential dependence of these neurons on high $\mathrm{Pbx}$ expression. Both $\mathrm{Pbx} 1$ and $\mathrm{Pbx} 3$ show highest expression in the cervical spinal cord where phrenic MNs are located when compared to the rest of the spinal cord, suggesting that high levels of the two factors are required in this population. A reduction of $\mathrm{Pbx}$ levels by $50 \%$ is sufficient to prevent the induction of all PMC markers but only partially affects $L M C$ and PGC induction. Our data underscores that in addition to the temporal and spatial restriction of TF expression, robustness of expression, an often-underappreciated dimension of developmental programs, is also a significant determinant of MN identity.

\section{Mechanisms of Top2 $\beta$ action}

In addition to downregulation of Hox and $P b x$ genes and impact on early $\mathrm{MN}$ specification programs, the deletion of Top2 $\beta$ may also influence the expression of a cohort of MN specific genes involved in later aspects of development such as synaptogenesis. A screen for genes downregulated in cortical neurons in Top $2 \beta$ mutants at multiple time points revealed a high number of affected genes, raising the possibility that Top $2 \beta$ may have a more global role in transcription throughout development (King et al., 2013). It is also possible that the absence of PMCspecific genes and LMC pool markers such as Pea3 and Scip is a direct result of their transcriptional regulation by Top2 $\beta$. While we cannot completely rule out these possibilities our data suggest that the defects we observe are mediated through a small set of Top2 $\beta$ target genes rather than a global effect on transcription.

Interestingly, a microarray screen in the embryonic brain identified $\mathrm{Pbx} 1$ and $\mathrm{Pbx} 3$ as being downregulated in Top2 $\beta$ mutant mice, suggesting that a common set of genes is under Top2 $\beta$ regulation that can influence different functions depending on the neuronal cell type (Lyu et al., 2006). The PMC-specific marker ALCAM was also identified in this screen, but unlike its complete absence from phrenic MNs, it was only slightly downregulated in Top2 $\beta-/-$ brain, suggesting that the dramatic change we observe likely results from a defect in PMC specification rather than a direct effect of Top2 $\beta$ on ALCAM transcription. Consistent with this idea a number of genes that are affected in Top2 $\beta$ mutant brains do not exhibit Top2 $\beta$ binding at their promoter regions, indicating that some expression changes are an indirect result of TF downregulation. It has been suggested that the transcription of long genes, including autism-spectrum disorder risk genes, is disproportionately affected in the absence of Top2 $\beta$ activity (King et al., 2013). Pbx1 and Pbx3 are both over $200 \mathrm{~kb}$ in length, making them likely direct targets of Top2 $\beta$. However, we also observe differential effects on Hox protein expression, despite the similar short length of the encoding genes, suggesting that gene length may not be the only determinant for Top2 $\beta$ regulation. Defining the full repertoire of genes affected in Top2 $\beta$ mutants and distinguishing between Top2 $\beta$ direct and indirect targets in MNs will further illuminate the role of this protein in MN development.

\section{Robust transcriptional networks and motor circuit assembly}

The complex phenotypes observed in Top2 $\beta$ mutants result from a reduction in the expression of key TFs that act during early $\mathrm{MN}$ development. Our findings highlight the importance of titrating TF levels during neuronal specification. In MNs for example, robust expression of FoxP1 leads to the acquisition of LMC identity, while low levels of FoxP1 underlie PGC specification (Dasen et al., 2008). The differential effects seen on distinct motor columns in Top2 $\beta$ mutants indicate that certain MN subtypes are more sensitive to even small fluctuations in TF expression (Fig. 10). The specification of PMC neurons is dramatically halted in Top $2 \beta-/-$ mice indicating that there is a critical requirement for high $\mathrm{Pbx}$ expression in the induction of PMC-specific genes. In contrast, LMC-specific Raldh2 expression, which is abolished in $\mathrm{Pbx} 1 / 3$ mutants, persists in Top2 $\beta$ mutants, indicating a less stringent requirement for high $\mathrm{Pbx}$ levels for the expression of LMC determinants. Our data suggests that the degree of robustness of transcriptional regulatory networks, established through the activity of Top $2 \beta$, is a critical determinant of neuronal cell identity programs and serves as an additional strategy employed in the nervous system to generate cell diversity. An intriguing possibility is that Top2 $\beta$ also acts in multiple interneuron populations in the spinal cord to initiate further subtype specification. In support of this idea, Top2 $\beta$-/- mice show changes in the localization of Lhx3+ interneurons in the spinal cord (Fig. $9 H$ ). Our findings establish Top2 $\beta$ as a critical mediator in the assembly of motor circuits and Top $2 \beta$ mutant mice will provide a powerful tool to further dissect the transcriptional pathways that give rise to diverse populations of neurons in the mammalian spinal cord.

\section{References}

Arber S, Han B, Mendelsohn M, Smith M, Jessell TM, Sockanathan $S$ (1999) Requirement for the homeobox gene $\mathrm{Hb9}$ in the consolidation of motor neuron identity. Neuron 23:659-674. Medline

Bel-Vialar S, Itasaki N, Krumlauf R (2002) Initiating Hox gene expression: in the early chick neural tube differential sensitivity to FGF and RA signaling subdivides the HoxB genes in two distinct groups. Development 129:5103-5115.

Dasen JS, Tice BC, Brenner-Morton S, Jessell TM (2005) A Hox regulatory network establishes motor neuron pool identity and target-muscle connectivity. Cell 123:477-491. CrossRef

Dasen JS, De Camilli A, Wang B, Tucker PW, Jessell TM (2008) Hox repertoires for motor neuron diversity and connectivity gated by a single accessory factor, FoxP1. Cell 134:304-316. CrossRef 
De Marco Garcia NV, Jessell TM (2008) Early motor neuron pool identity and muscle nerve trajectory defined by postmitotic restrictions in Nkx6.1 activity. Neuron 57:217-231. CrossRef

Golden MG, Dasen JS (2012) Polycomb repressive complex 1 activities determine the columnar organization of motor neurons. Genes Dev 26:2236-2250. CrossRef

Hanley O, Zewdu R, Cohen LJ, Jung H, Lacombe J, Philippidou P, Lee DH, Selleri L, Dasen JS (2016) Parallel Pbx-dependent pathways govern the coalescence and fate of motor columns. Neuron 91:1005-1020. CrossRef

Jung H, Lacombe J, Mazzoni EO, Liem KF Jr, Grinstein J, Mahony S, Mukhopadhyay D, Gifford DK, Young RA, Anderson KV, Wichterle H, Dasen JS (2010) Global control of motor neuron topography mediated by the repressive actions of a single hox gene. Neuron 67:781-796. CrossRef

King IF, Yandava CN, Mabb AM, Hsiao JS, Huang HS, Pearson BL, Calabrese JM, Starmer J, Parker JS, Magnuson T, Chamberlain SJ, Philpot BD, Zylka MJ (2013) Topoisomerases facilitate transcription of long genes linked to autism. Nature 501:58-62. CrossRef

Li Y, Hao H, Tzatzalos E, Lin RK, Doh S, Liu LF, Lyu YL, Cai L (2014) Topoisomerase llbeta is required for proper retinal development and survival of postmitotic cells. Biol Open 3:172-184. CrossRef

Liu JP, Laufer E, Jessell TM (2001) Assigning the positional identity of spinal motor neurons: rostrocaudal patterning of Hox-c expression by FGFs, Gdf11, and retinoids. Neuron 32:997-1012. CrossRef

Lyu YL, Wang JC (2003) Aberrant lamination in the cerebral cortex of mouse embryos lacking DNA topoisomerase Ilbeta. Proc Natl Acad Sci USA 100:7123-7128. CrossRef Medline

Lyu YL, Lin CP, Azarova AM, Cai L, Wang JC, Liu LF (2006) Role of topoisomerase Ilbeta in the expression of developmentally regulated genes. Mol Cell Biol 26:7929-7941. CrossRef

Machado CB, Kanning KC, Kreis P, Stevenson D, Crossley M, Nowak M, lacovino M, Kyba M, Chambers D, Blanc E, Lieberam I (2014) Reconstruction of phrenic neuron identity in embryonic stem cell-derived motor neurons. Development 141:784-794. CrossRef

Madabhushi R, Gao F, Pfenning AR, Pan L, Yamakawa S, Seo J, Rueda R, Phan TX, Yamakawa H, Pao PC, Stott RT, Gjoneska E, Nott A, Cho S, Kellis M, Tsai LH (2015) Activity-induced DNA breaks govern the expression of neuronal early-response genes. Cell 161:1592-1605. CrossRef

McKinnon PJ (2016) Topoisomerases and the regulation of neural function. Nat Rev Neurosci 17:673-679. CrossRef Medline

Merabet S, Mann RS (2016) To be specific or not: the critical relationship between Hox and TALE proteins. Trends Genet 32:334347. CrossRef Medline

Nevin LM, Xiao T, Staub W, Baier H (2011) Topoisomerase Ilbeta is required for lamina-specific targeting of retinal ganglion cell axons and dendrites. Development 138:2457-2465. CrossRef

Nitiss JL (1998) Investigating the biological functions of DNA topoisomerases in eukaryotic cells. Biochim Biophys Acta 1400:63-81. CrossRef

Philippidou P, Dasen JS (2013) Hox genes: choreographers in neural development, architects of circuit organization. Neuron 80:12-34. CrossRef

Philippidou P, Walsh CM, Aubin J, Jeannotte L, Dasen JS (2012) Sustained Hox 5 gene activity is required for respiratory motor neuron development. Nat Neurosci 15:1636-1644. CrossRef Medline

Schaller S, Buttigieg D, Alory A, Jacquier A, Barad M, Merchant M, Gentien D, de la Grange P, Haase G (2017) Novel combinatorial screening identifies neurotrophic factors for selective classes of motor neurons. Proc Natl Acad Sci USA 114:E2486-E2493. CrossRef

Tiwari VK, Burger L, Nikoletopoulou V, Deogracias R, Thakurela S, Wirbelauer C, Kaut J, Terranova R, Hoerner L, Mielke C, Boege F, Murr R, Peters AH, Barde YA, Schübeler D (2012) Target genes of Topoisomerase $\| \beta$ regulate neuronal survival and are defined by their chromatin state. Proc Natl Acad Sci USA 109:E934-E943. CrossRef

Tsuchida T, Ensini M, Morton SB, Baldassare M, Edlund T, Jessell TM, Pfaff SL (1994) Topographic organization of embryonic motor neurons defined by expression of LIM homeobox genes. Cell 79:957-970. CrossRef

Wang JC (2002) Cellular roles of DNA topoisomerases: a molecular perspective. Nat Rev Mol Cell Biol 3:430-440. CrossRef Medline

Yang X, Li W, Prescott ED, Burden SJ, Wang JC (2000) DNA topoisomerase Ilbeta and neural development. Science 287:131-134. Medline 